\title{
Teleneurology Applicability In 2020: Consequences of Remote Neurology Consult
}

\author{
Christopher Gaeta* \\ Department of Emergency Medicine, Children's Hospital of Philadelphia, USA
}

Submission: January 11, 2020; Published: January 21, 2020

*Corresponding author: Christopher Gaeta, Department of Emergency Medicine, Children's Hospital of Philadelphia, Philadelphia, New York City, 734 Schuylkill Ave, Philadelphia, PA 19146, USA

\begin{abstract}
Limited retrospective reviews of recent publications exist concerning telemedicine consultations by neurologists. The rapid growth in teleological transformation in the delivery of care has further prompted more evidence informed research about the specific challenges and benefits to using telehealth for neurologist patient consultations. Therefore, this review seeks to revisit the most recent literary reviews and studies to suggest a holistic and multifaceted perspective to explore the impacts of Teleneurology.
\end{abstract}

Keywords: Telemedicine; Telehealth; Medical innovation; Neurology consult; Delivery of care

\section{Introduction}

Telemedicine has rapidly grown in remote areas of the United States as a pragmatic resource continuing to garner a heightened acceptance and utilization in the medical community. However, the challenges presented in clinical settings and implementation of telemedicine present legal and diagnostic barriers that hinder the further integration of telemedical services in the neurology specialty [1-2]. Limitations uniquely affecting neurology are particular exclusive factors limiting lower income patients from attaining neurological specialty care due to cost and limited availability, and also for middle and upper income patients who have difficulty finding a local provider or physically go to a clinic due to any host of potential disabilities [3]. The current publications relating to Teleneurology are largely based on retrospective and qualitative factors discussing the anticipated benefits and negatives [3]. By combining these review articles with the scarce body of clinical research on patient experience and outcome of using Teleneurology, this review aims to provide an updated synthesis of the multifactorial and overarching conclusions from the primary bodies of research.

\section{Results \& Discussion}

Limited quantitative studies have adequate associated or presented significant concluding data results for tele neurological services. In particular, the most pertinent, larger statistical study on telemedicine survey methods seeking to measure outcomes of these consultations, showed from the thirty-six studies outcomes of satisfaction (with telemedicine, showed) high levels of satisfaction across all these dimensions (of measurement). However, just as significant is the paper's subsequent acknowledgement that current evidence base lacks clarity in terms of how satisfaction is defined and measured [4]. Of the larger body of research, the most relevant studies focused on the impact of these services begins with a 2014 survey of over three hundred rural veterans that used telemedical consults for neurological impairments. The results strongly concluded that patients were highly satisfied with the convenience and quality of their Teleneurology visit, and the neurology providers were convinced that neurologic care to both Teleneurology and clinic follow-up patients was equivalent [5].

Nonetheless, just as impressive was the potential financial benefits that this study highlighted with its results that calculated an average time savings of $5 \mathrm{~h}$ and 325 miles driven, plus at least $\$ 48,000$ total cost savings [5]. The optimistic results of this larger scale study is further echoed by a more recent 2019 study. The cohort of nearly double the amount of veterans in this instance gathered similar survey feedback methods from the 1,200 subjects and their providers. Both groups noted a similarly positive reception of the service and concludes that our rural veteran patients and neurology staff overwhelmingly found high quality patient care can be delivered via Teleneurology for 
a variety of chronic neurologic problems and was comparable to care delivered in neurology face-to-face clinics [6]. Though there is limited available data on associated impacts of Teleneurology in communities, the preliminary research evinces an optimistic outlook in terms of increased convenience, cost effectiveness, and overall satisfaction with remote neurology visits. Lastly, though the noted studies above provided exceptional preliminary data, it is critical that future studies attempt to measure the effectiveness of telemedicine in all populations rather than veterans in a certain segment of the country.

\section{References}

1. Wechsler LR, Tsao JW, Levine SR, Swain-Eng RJ, Adams RJ, et al. (2013) Teleneurology applications: Report of the Telemedicine Work Group of the American Academy of Neurology. Neurology 80(7): 670-676.
2. Wootton R, Bonnardot L (2015) Telemedicine in low-resource settings. Front Public Health 3: 3.

3. Whitten P, Holtz B, Laplante C (2010) Telemedicine: What have we learned? Appl Clin Inform 1(2): 132-141.

4. Orlando JF, Beard M, Kumar S (2019) Systematic review of patient and caregivers' satisfaction with telehealth videoconferencing as a mode of service delivery in managing patients' health. PLoS ONE 14(8): e0221848.

5. Edmunds M, Tuckson R, Lewis J (2017) An Emergent Research and Policy Framework for Telehealth. EGEMS (Wash DC). 5(2): 1303.

6. Davis LE, Coleman J, Harnar J, King MK (2014) Teleneurology: Successful Delivery of Chronic Neurologic Care to 354 Patients Living Remotely in a Rural State. Telemed J E Health 20(5): 473-477.

\section{Your next submission with Juniper Publishers will reach you the below assets}

- Quality Editorial service

- Swift Peer Review

- Reprints availability

- E-prints Service

- Manuscript Podcast for convenient understanding

- Global attainment for your research

- Manuscript accessibility in different formats

( Pdf, E-pub, Full Text, Audio)

- Unceasing customer service

Track the below URL for one-step submission

https://juniperpublishers.com/online-submission.php 